\title{
Is the perceived placebo effect comparable between adults and children? A meta-regression analysis
}

\author{
Perrine Janiaud' ${ }^{1}$, Catherine Cornu ${ }^{1,2,3}$, Audrey Lajoinie' ${ }^{1}$, Amina Djemli' ${ }^{1}$ Michel Cucherat ${ }^{2}$ and Behrouz Kassai ${ }^{1,2,3}$
}

\begin{abstract}
BACKGROUND: A potential larger perceived placebo effect in children compared with adults could influence the detection of the treatment effect and the extrapolation of the treatment benefit from adults to children. This study aims to explore this potential difference, using a meta-epidemiological approach.

METHODS: A systematic review of the literature was done to identify trials included in meta-analyses evaluating a drug intervention with separate data for adults and children. The standardized mean change and the proportion of responders (binary outcomes) were used to calculate the perceived placebo effect. A meta-regression analysis was conducted to test for the difference between adults and children of the perceived placebo effect.
\end{abstract}

RESULTS: For binary outcomes, the perceived placebo effect was significantly more favorable in children compared with adults $(\beta=0.13$; $P=0.001)$. Parallel group trials $(\beta=-1.83$; $P<0.001)$, subjective outcomes $(\beta=-0.76 ; P<0.001)$, and the disease type significantly influenced the perceived placebo effect.

CONCLUSION: The perceived placebo effect is different between adults and children for binary outcomes. This difference seems to be influenced by the design, the disease, and outcomes. Calibration of new studies for children should consider cautiously the placebo effect in children.

$\mathbf{T}$ he placebo has been defined as a pharmacological inert substance and the placebo effect as "any effects attributable to a pill, potion or procedure, but not to its pharmacodynamics or specifics properties" (1). Its use in clinical trials became the mean to control for psychological effects associated to the administration of a substance. Researchers soon became aware that the administration of a placebo could result into a relief or an improvement of symptoms. Such effect became known as the placebo effect (2). Placebo effect is usually measured in randomized controlled trials by the nonblinded comparison between placebo and no-treatment groups (3). Consequently, the true effect of placebo interventions is potentially biased by the type of outcomes, cointervention, selective publication, and reporting (4). Placebo research is not limited, however, to the field of clinical trials, and has expanded to the field of neurobiology. Pharmacology, brain imaging techniques, genetics, and animal models have shown, for instance, the capacity of the placebo to mimic active drugs and activate the same brain areas (5), the association of the placebo response with some genotypes in some conditions, and the important role of prefrontal cortex functioning impairment in reducing placebo response (6). The similarity in the mechanism of action between the placebo and the active substance can be explained partly by Pavlovian conditioning or learning by patients of the effect of the active drug (7), and also by expectation, social propagation of expectations, or the Hawthorn effect (5).

Since 1955 with Beecher's statement on the high degree of therapeutic efficacy of placebos (8), the placebo effect, also known as the "true" placebo effect, has been misinterpreted and confounded with the "perceived placebo effect" (9). The perceived placebo effect, the term we will use in this article to avoid any confusion with the placebo effect, equals the "true" placebo effect $(10,11)$ plus other factors that may explain the improvement or worsening of the patients' outcomes in the placebo arm of clinical trials. Those factors include the natural history with the potential of spontaneous regression of the disease, the regression to the mean, the use of concomitant treatments, the experimental subordination, the conditioned responses, and other unknown factors. Experimental subordination means that the subject learns what the expected effects could be and this conditions his actual response.

As it seems difficult to conduct research in children without direct therapeutic benefits, the placebo effect has been commonly measured from adult trials with a placebo group vs. an untreated group. For instance, a meta-analysis focusing on placebo interventions included 202 randomized placebo trials with a no-treatment control group. Authors showed that there was a significant overall effect of placebo and found that placebo interventions can influence patientreported outcomes. Among the 202 trials, 21 (10.4\%) included pediatric subjects, and one included newborns. There were no significant differences between the placebo and no-treatment group for 16 of the pediatric trials, 3 showed a significant difference and 2 had no exploitable

'UMR 5558, CNRS, Claude Bernard University Lyon 1, Lyon, France; ${ }^{2}$ Department of Clinical Pharmacology, CHU Lyon, Lyon, France; ${ }^{3}$ EPICIME-Clinical Investigation Center, 


\section{Systematic Review}

outcomes (3). Another narrative review identified 9,000 citations using the terms "placebo" and "children", among which only $50(2.5 \%)$ studied, but not measured, the perceived placebo effect in children (12).

Because the perceived placebo effect has been mostly studied in adults, its extent is often extrapolated from adults to children. Children and adults, however, differ in terms of physiological development, physiopathology, pharmacokinetics, and pharmacodynamics but probably also in terms of perceived placebo effect $(13,14)$. A recent meta-analysis of antiepileptics suggests that the perceived placebo effect might be higher in children than in adults (15). The authors measured the perceived placebo effect by measuring the difference between the proportion of responders between the start and end of the study in the placebo group. The difference between children and adults could be attributed to a greater regression to the mean in children or to a strong placebo-by-proxy effect. Placebo-by-proxy effect occurs when children are receiving more attention and parents are more eager to report favorable outcomes in the pediatric population (15-17).

In this study, we aimed at exploring the differential perceived placebo effect between adults and children in all available published meta-analyses. The main objective of this systematic review of reviews is to confirm a potential more favorable perceived placebo effect in children compared with adults.

\section{RESULTS}

We identified 3,484 reviews. After screening of titles and abstracts, and the exclusion of irrelevant and duplicates, 762 reviews were screened (Figure 1). Seventy-five reviews, not reporting the difference between the start and end of the study, were also excluded. Thirty-five reviews, including 179 trials with adult and 117 with pediatric participants, were finally analyzed (15,18-51) (Supplementary Table S1 online). From these reviews, 19 assessed the risk of bias $(18,20,22,25,26,28,29,32,35,37-41,44,46,49-51), 6$ reported only the Jadad score $(15,19,21,36,45,48), 4$ assessed only the allocation concealment $(34,42,43,47)$, and 6 did not assess quality $(23,24,27,30,31,33)$. Overall, 13382 adult and 5417 pediatric participants were enrolled in the placebo groups.

\section{Results for Continuous Outcomes}

Two hundred fourteen trials were included, 126 in adults and 88 in children, covering 13 different therapeutic indications. The three most common therapeutic indications were asthma (62 trials), exercise-induced asthma (54 trials), and atopic dermatitis (24 trials) (Table 1). Crossover exercise-induced asthma trials (50 trials) did not report results for each period.

Overall, children's (standardized mean change $-0.32 ; 95 \% \mathrm{CI}$ $(-0.52 ;-0.12)$ ) and adults' (standardized mean change -0.11 ; $95 \%$ CI $(-0.24 ; 0.02)$ ) outcomes deteriorated with placebo with no significant difference between children and adults $(\beta=$ $-0.20 ; P=0.30$; Figure 2; Supplementary Table S2 online and Supplementary Figure S1 online).

\section{Sensitivity Analysis for Continuous Outcomes}

The sensitivity analyses showed a significant difference between adults' and children's perceived placebo effect when only crossover trials $(\beta=0.5 ; P=0.03)$ and only objective outcomes $(\beta$ $=-0.67 ; P=0.003)$ were included. For crossover trials and objective outcomes, children and adults showed an unfavorable effect with placebo. Perceived placebo effect remained unchanged for each stratum of diseases (Supplementary Table S2 online and Supplementary Figure S1 online).

\section{Results for Binary Outcomes}

Eighty-two trials, 53 in adults and 29 in children, reported binary outcomes in 6 different therapeutic indications. In resistant partial epilepsy, 10 crossover trials reported only the first period. All trials that defined responders as 50\% reduction in the number of seizures were in parallel groups.

Binary outcomes improved more with placebo in children (responders proportion $0.32 ; 95 \% \mathrm{CI}(0.26 ; 0.39)$ ) than in adults (responders proportion $=0.19 ; 95 \% \mathrm{CI}(0.15 ; 0.23)$, with a significant difference between adults and children $\beta=0.13 ; P=0.001$; Figure 3; Supplementary Table S3 online and Supplementary Figure $\mathbf{S 2}$ online).

\section{Sensitivity Analysis for Binary Outcomes}

For drug resistant partial epilepsy, children (responders proportion $0.18 ; 95 \% \mathrm{CI}(0.14 ; 0.22))$ improved more with placebo than adults (responders proportion 0.13 ; $95 \%$ CI $(0.10$; $0.15)$; with a significant difference between adults and children $\beta=0.06, P=0.02$; Supplementary Table S3 online and Supplementary Figure S2 online).

\section{Other Factors than Population Influencing the Perceived Placebo Effect}

The univariate meta-regression for binary outcomes showed that participants with asthma $((\beta=0.36 ; P<0.001)$, depression $(\beta=0.29 ; P<0.001)$, and drug-resistant partial epilepsy $(\beta=$ $-0.22 ; P=0.001)$ improved more with placebo compared with other diseases. All the trials were parallel groups and all used subjective outcomes, the univariate and multivariate metaregression were not feasible (Supplementary Table S3 online and Supplementary Figure S2 online).

For continuous outcomes, participants with asthma $((\beta=$ $0.68 ; P=0.001)$, atopic dermatitis $(\beta=1.21 ; P<0.001)$, bipolar disorder $(\beta=1.21 ; P=0.001)$ improved with placebo. Those with exercise-induced asthma $(\beta=-2.23 ; P<0.001)$, however, deteriorated with placebo (Supplementary Table S2 online and Supplementary Figure S1 online).

The univariate meta-regression also showed a larger improvement with placebo in parallel group (standardized mean change $0.24 ; 95 \%$ CI $(0.14 ; 0.34)$ ) compared with crossover studies (standardized mean change $-1.81 ; 95 \%$ CI $(-1.60 ;-2.01)$ ), and for subjective (standardized mean change 0.75 ; $95 \%$ CI $(0.54 ; 0.95))$ compared with objective outcomes (standardized mean change -0.50 ; $95 \%$ CI $(-0.61$; $-0.39)$ ) 


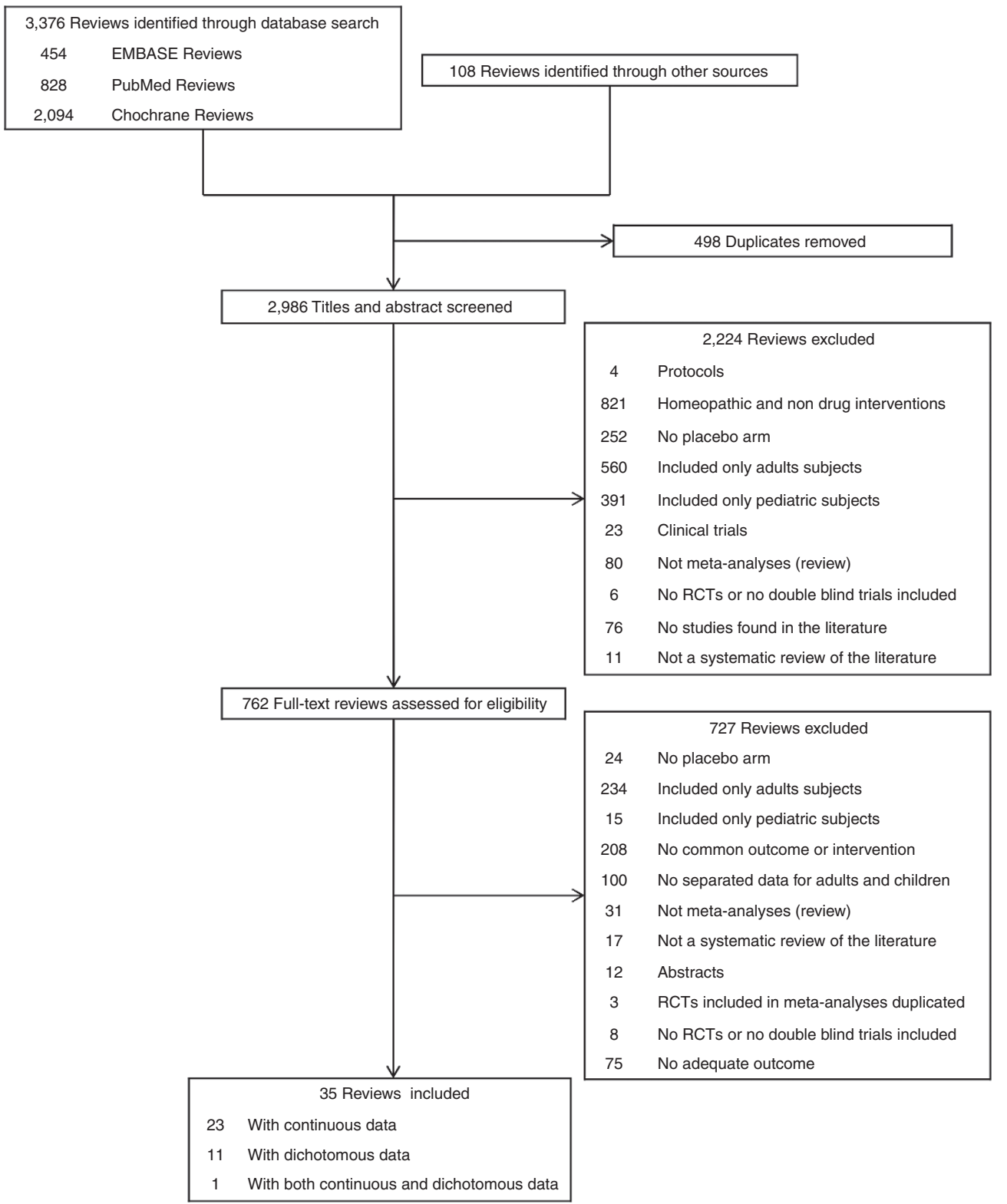

Figure 1. Flowchart of the literature search.

In the multivariate model, population, design, and outcome, explained $64.03 \%$ of the between studies variance. The design $(\beta=-1.83 ; P<0.000)$, the outcome $(\beta=-0.76 ; P<0.000)$ significantly influenced the perceived placebo effect. The difference between children and adults remained nonsignificant in the multivariate model $(\beta=0.09 ; P=0.526)$.

\section{DISCUSSION}

In our broad overview, we found a significant difference in the perceived placebo effect between adults and children for binary outcomes. Overall, when binary outcomes are used children tend to improve more with placebo compared with adults. The results found for binary outcomes are coherent with Rheims et al. (15) study and the literature $(12,16)$. The disease, and probably the outcomes and the design seem to influence the perceived placebo effect on binary outcomes and need to be investigated in future studies.

For continuous outcomes, we did not show any difference between adults and children on the perceived placebo effect. The perceived placebo effect seemed to be influenced by the disease, the design of the studies and by type of outcome measures. It increases when the design used was parallel groups compared with crossover as it was shown in a previous report (52). The effect observed with crossover trials for continuous outcomes could be explained by the regression to the mean potentially more important in the first compared with the second period. Patients receiving placebo during the first period may benefit from a favorable natural course of the disease and accentuate the regression to the mean (53). Also, the regression to the mean, as part of the perceived placebo effect, could 
Table 1. Characteristics of included randomized controlled trials

\begin{tabular}{|c|c|c|c|c|c|c|}
\hline \multirow[b]{2}{*}{ Variable } & \multicolumn{3}{|c|}{$\begin{array}{l}\text { Continuous } \\
\text { Outcomes }\end{array}$} & \multicolumn{3}{|c|}{ Binary Outcomes } \\
\hline & Total & Adults & Children & Total & Adults & Children \\
\hline \multicolumn{7}{|l|}{ Design: $n$ studies (\%) } \\
\hline Crossover & 50 & $19(38 \%)$ & $31(62 \%)$ & & & \\
\hline Objective & 159 & $101(64 \%)$ & $58(36 \%)$ & & & \\
\hline Subjective & 55 & $25(45 \%)$ & $30(55 \%)$ & 82 & $53(65 \%)$ & $29(35 \%)$ \\
\hline \multicolumn{7}{|l|}{ Diseases: $n$ studies (\%) } \\
\hline Anemia & 10 & $9(90 \%)$ & $1(10 \%)$ & & & \\
\hline Bipolar disorder & 15 & $11(73 \%)$ & $4(27 \%)$ & 7 & $2(29 \%)$ & $5(71 \%)$ \\
\hline Blood lipidic levels & 13 & $12(92 \%)$ & $1(8 \%)$ & & & \\
\hline Chronic plaque psoriasis & 8 & $7(88 \%)$ & $1(13 \%)$ & & & \\
\hline Cystic fibrosis & 9 & $3(33 \%)$ & $6(67 \%)$ & & & \\
\hline Depression & & & & 15 & $10(67 \%)$ & $5(33 \%)$ \\
\hline Drug resistant partial epilepsy & & & & 48 & $10(21 \%)$ & $38(79 \%)$ \\
\hline Exercise induced asthma & 54 & $20(37 \%)$ & $34(63 \%)$ & & & \\
\hline Generalized anxiety disorder & 2 & $1(50 \%)$ & $1(50 \%)$ & & & \\
\hline Osteogenesis imperfecta & 2 & $1(50 \%)$ & $1(50 \%)$ & & & \\
\hline
\end{tabular}

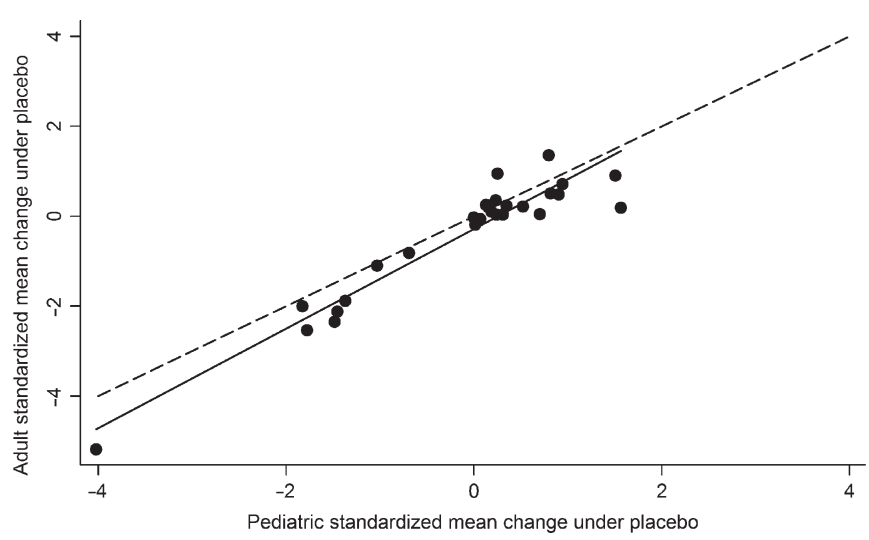

Figure 2. Linear regression of the perceived placebo effect in children compared with adults for continuous outcomes. Each circle represents pooled data from pediatric ( $x$-axis) and adult ( $y$-axis) studies for the same disease and with the same drug. When the circle is above the diagonal (dashed line) the perceived placebo effect is lower and when it is below, higher, in children compared with adults.

be diluted by taking the mean effect with placebo regardless of the periods. Patients who receive the drug first and then the placebo may also show a higher placebo response because of a carry-over effect or a conditioning learning effect (54). To be able to investigate further the influence of the design on the perceived placebo effect the outcome measures for the different treatment periods should be analyzed, but they are rarely reported.

The larger improvement with placebo for subjective outcomes might be explained by the measurement bias when these outcomes are used to select patients participating to the trials, and by the regression to the mean (55). The way trials are conducted and patients informed can influence the placebo response (3). Another explanation could be that children show a stronger placebo-by-proxy effect (17). It has also been shown that the mood and belief of the adult caregiver can influence the placebo response in children (56). Conditioning learning plays also an important role in the response of children to the placebo. Children have greater capacity in associative learning (12). This learning process can be emphasized in crossover trials (54).

Our study has some limits. Confounding factors cannot be excluded because of the absence of randomization between compared groups. The difference between the start and end of the study in the placebo arm can also reflect the effect of 


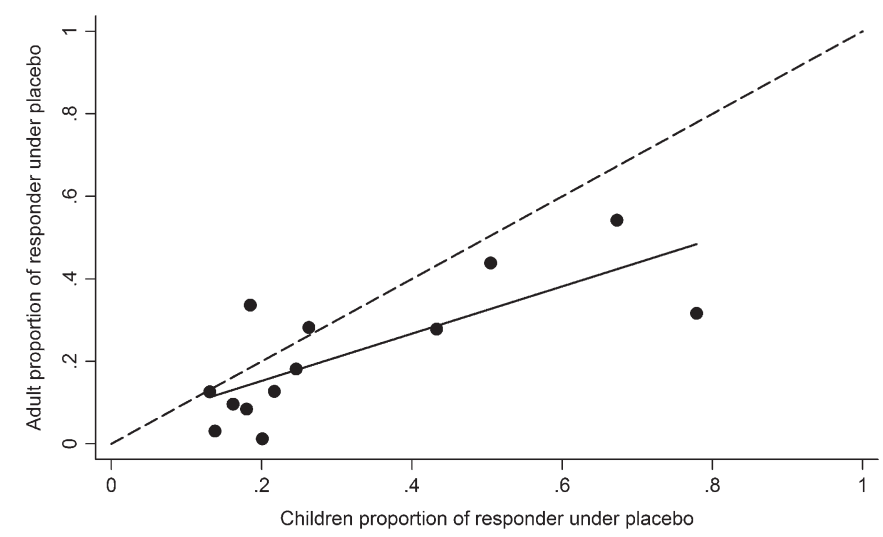

Figure 3. Linear regression of the perceived placebo effect in children compared with adults for binary outcomes. Each circle represents pooled data from pediatric $x$-axis) and adult ( $y$-axis) studies. When the circle is above the diagonal (dashed line) the perceived placebo effect is lower and when it is below, higher, in children compared with adults.

concomitant treatments and the natural history of the disease. In the absence of no-treatment arm, our analysis assumes that the natural history of the disease and the effect of concomitant treatments could be similar in adults and children. Also, for binary outcomes, we were not able to explore the influence of the design and the outcomes measures on the perceived placebo effect. Furthermore, incomplete reports of crossover trials did not allow us to further explore the importance of the regression to the mean in each treatment periods. The major limit on the validity of our study is shared by other recent publications $(15,16,57,58)$ suggesting a higher perceived placebo response in children compared with adults. In summary, our results underline that the difference observed in these reviews should be interpreted cautiously, because they are highly influenced by the disease, the design and the outcomes. It is not clear whether for binary outcomes the difference between adults and children in the perceived placebo effect could disappear when adjusting for these variables.

In order to avoid missing a potential treatment benefit, when performing randomized trials in children, calibration should take account for the design, disease, and type of outcomes.

\section{METHODS}

\section{Literature Search}

The unit of research for our work was the trial and those were identified through a systematic review of meta-analyses in the literature. Three electronic databases (PubMed (US National Library of Medicine, Bethesda, Maryland), Embase (Elsevier, Amsterdam, Netherlands) and the Cochrane Library (John Wiley \& Sons, Chichester, UK)) were searched for meta-analyses, with no limitation, on language, dates, diseases or treatments. The last bibliographic search was done on 11 February 2015. The following search terms were used: (Child OR preschool OR infant OR adolescent) AND adult*) AND placebo. For PubMed, we specified the type of study ("meta-analysis"). For EMBASE, we specified the following filters: "human" and "meta-analysis".

\section{Meta-analyses Selection}

Meta-analyses were eligible when they included randomized controlled trials (RCTs) in adults and children that were double-blinded, placebo-controlled, and reported separately their results for adults and children. All types of pharmacological treatments, except for homeopathic treatments, were eligible. The age limit between adults and children, when necessary, was arbitrarily set at $18 \mathrm{y}$. The RCTs from the included meta-analyses were classified according to their therapeutic indications. When two reviews reported the same RCTs, the review with the most complete information was considered. When both reported the same information, the most recent review was considered.

Three authors (P.J., B.K., A.D.) reviewed all citation abstracts and excluded irrelevant studies according to prespecified exclusion criteria.

\section{Data Extraction}

The following information was extracted for each relevant trial included in the meta-analyses and entered into the database: (i) the design of the study (randomization, parallel group, crossover, and blinding); (ii) patient characteristics (adults or children, number of patients in the placebo and treatment arms, and the number of events and no-events in each arm for dichotomous data or the mean change from baseline to the end of study for each arms for continuous data); (iii) the disease (e.g., "asthma"); (iv) the drug used, when more than one drug was reported, data were extracted for each drug studied in the meta-analysis; (v) the drug's therapeutic class; (vi) the outcome; (vii) the dose for adults and the dose adjustment methods for children. Duplicated placebo groups, i.e., same RCTs included in different meta-analyses, were excluded.

The main outcome and the treatment benefit (number of events or effect size in each group) were extracted blindly from the original systematic review by three authors (P.J., C.C., A.L.). Differences were resolved by consensus.

\section{Quality Assessment}

We reported the quality assessment reported by the authors of the meta-analyses for each included RCT. We used the assessments reported in meta-analyses, the Cochrane assessment of risk of bias (59), and the five-point scoring instrument developed by Jadad and Enkin (60) or both.

\section{Outcome}

We extracted the primary outcome measured at the start and end of the study for adults and children. The outcomes were classified as subjective or objective. Subjective outcomes were any outcomes that were reported by the patient or family reported scale, or were subject to measurement bias (Supplementary Table S1 online). When a biological (cholesterol, $\mathrm{Hb}$ ) or device measurement (spirometer or body weight scale) was used, it was considered as an objective outcome.

\section{Dealing With Missing Data}

To fill out missing data, we consulted the original article and contacted authors of meta-analyses. For continuous outcome, we calculated or imputed missing values when the mean change from baseline or the SD was missing (59).

\section{Unit of Analysis Error}

The unit of analysis error occurs when dealing with crossover trials and multiple intervention groups. As we were interested in the perceived placebo effect, for crossover trials only data from the first period with placebo were considered. When the effect reported was calculated from the difference between the start and end of the study regardless of the periods (i.e., as if a parallel trial), we extracted the mean change from baseline only for the placebo periods. For multiple intervention groups, i.e., different doses vs. placebo, no adjustment was required (59).

\section{Statistical Analysis}

The perceived placebo effect was defined as the change in the outcome experienced by the patient in the placebo arms between the beginning (baseline) and the end of the trial.

For continuous outcomes, we calculated the standardized mean change and for dichotomous data the proportion of responders in the placebo arm. Standardized mean change $>0$ indicates improvement and $<0$ worsening of the outcomes. To assess a potential difference between children's and adults' perceived placebo effect; univariate 


\section{Systematic Review}

random-effect restricted maximum likelihood meta-regression analyses were performed. The meta-regression analyses included the following explanatory variables defined a priori: (i) population (children under the age of $18 \mathrm{y}$ coded as 1 or adults coded as 0 ); (ii) diseases (dummy variables created, disease of interest coded as 1 and other diseases coded as 0); (iii) design of study (crossover coded as 1 or parallel coded as 0); and (iv) type of outcome (objective coded as 1 or subjective coded as 0 ). The multivariate meta-regression included the population, design of the study, and outcome variables.

To adjust for multiple testing, the $t$-test from the Monte-Carlo permutation (with 10,000 replications) was used. When all trials were parallel groups or used only subjective outcomes, the multivariate meta-regression was not feasible. The unit of analysis was the trial. All analyses were performed using the Stata/IC12 software (StataCorp LP, College Station, TX).

\section{Sensitivity Analyses}

We conducted sensitivity analyses to test how robust are the potential differences between adults' and children's perceived placebo effect. At each step of the analysis, we excluded one of the following categories: crossover trials, parallel trials, trials using an objective outcome, trials using a subjective outcome. We also checked the robustness of our results for each disease separately.

\section{SUPPLEMENTARY MATERIAL}

Supplementary material is linked to the online version of the paper at http:// www.nature.com/pr

\section{ACKNOWLEDGMENTS}

B.K. and M.C. were responsible for the study concept and design. B.K., A.L., C.C., A.D., and P.J. were involved in the literature and data extraction. M.C., B.K., C.C., and P.J. were responsible for the data analysis and interpretation. B.K. and P.J. wrote the manuscript. All authors critically revised the manuscript. B.K. and P.J. were responsible for the editing of the manuscript. B.K. supervised the study and is the guarantor.

\section{STATEMENT OF FINANCIAL SUPPORT}

P.J. is currently receiving a grant from GlaxoSmithKline, France, for her three years $\mathrm{PhD}$ at the UMR 5558 CNRS. The funder had no role in study design, data collection and analysis, decision to publish, or preparation of the manuscript

\section{Disclosure: The authors have no conflict of interest.}

\section{REFERENCES}

1. Wolf S. The pharmacology of placebos. Pharmacol Rev 1959;11:689-704.

2. Boussageon R, Gueyffier F, Moreau A, Boussageon V. [The difficulty of measurement of placebo effect]. Therapie 2006;61:185-90.

3. Hrobjartsson A, Gotzsche PC. Placebo interventions for all clinical conditions. Cochrane Database Syst Rev 2010: CD003974.

4. Kaptchuk TJ, Kelley JM, Conboy LA, et al. Components of placebo effect: randomised controlled trial in patients with irritable bowel syndrome. BMJ 2008;336:999-1003.

5. Benedetti F. Placebo effects: from the neurobiological paradigm to translational implications. Neuron 2014;84:623-37.

6. Stein N, Sprenger C, Scholz J, Wiech K, Bingel U. White matter integrity of the descending pain modulatory system is associated with interindividual differences in placebo analgesia. Pain 2012;153:2210-7.

7. Ernst E. Placebo: new insights into an old enigma. Drug Discov Today 2007;12:413-8.

8. Beecher HK. The powerful placebo. J Am Med Assoc 1955;159:1602-6.

9. Ernst E, Resch KL. Concept of true and perceived placebo effects. BMJ 1995;311:551-3.

10. Fisher S. Nonspecific factors as determinants of behavioral response to drugs. In: Di Mascio A, Shader RI (eds.). Clinical Handbook of Psychopharmacology. New York: Science House 1971: 17-39.

11. Gøtzsche PC. Is there logic in the placebo? Lancet 1994;344:925-6.

12. Weimer K, Gulewitsch MD, Schlarb AA, Schwille-Kiuntke J, Klosterhalfen S, Enck P. Placebo effects in children: a review. Pediatr Res 2013;74: 96-102.
13. Klassen TP, Hartling L, Craig JC, Offringa M. Children are not just small adults: the urgent need for high-quality trial evidence in children. PLoS Med 2008;5:e172.

14. Janiaud P, Lajoinie A, Cour-Andlauer F, et al. Different treatment benefits were estimated by clinical trials performed in adults compared with those performed in children. J Clin Epidemiol 2015;68:1221-31.

15. Rheims S, Cucherat M, Arzimanoglou A, Ryvlin P. Greater response to placebo in children than in adults: a systematic review and meta-analysis in drug-resistant partial epilepsy. PLoS Med 2008;5:e166.

16. Curie A, Yang K, Kirsch I, et al. Placebo responses in genetically determined intellectual disability: a meta-analysis. PLoS One 2015;10:e0133316.

17. Grelotti DJ, Kaptchuk TJ. Placebo by proxy. BMJ 2011;343:d4345.

18. Adams Nick P, Bestall Janine C, Lasserson Toby J, Jones P, Cates Christopher J. Fluticasone versus placebo for chronic asthma in adults and children. Cochrane Database of Syst Rev 2008: CD003135.

19. Adams Nick P, Bestall Janine C, Malouf R, Lasserson Toby J, Jones P. Beclomethasone versus placebo for chronic asthma. Cochrane Database of Syst Rev 2005: CD002738.

20. Adams Stephen P, Sekhon Sarpreet S, Wright James M. Lipid-lowering efficacy of rosuvastatin. Cochrane Database of Syst Rev 2014: CD010254.

21. Ashcroft DM, Dimmock P, Garside R, Stein K, Williams HC. Efficacy and tolerability of topical pimecrolimus and tacrolimus in the treatment of atopic dermatitis: meta-analysis of randomised controlled trials. BMJ 2005;330:516.

22. Barbui C, Cipriani A, Patel V, Ayuso-Mateos JL, van Ommeren M. Efficacy of antidepressants and benzodiazepines in minor depression: systematic review and meta-analysis. Br J Psychiatry 2011;198:11-6, sup 1.

23. Beyenburg S, Stavem K, Schmidt D. Placebo-corrected efficacy of modern antiepileptic drugs for refractory epilepsy: systematic review and metaanalysis. Epilepsia 2010;51:7-26.

24. Björkhem-Bergman L, Asplund AB, Lindh JD. Metformin for weight reduction in non-diabetic patients on antipsychotic drugs: a systematic review and meta-analysis. J Psychopharmacol 2011;25:299-305.

25. Bonini M, Di Mambro C, Calderon Moises A, et al. Beta2-agonists for exercise-induced asthma. Cochrane Database of Syst Rev 2013: CD003564.

26. Brown R, Taylor Matthew J, Geddes J. Aripiprazole alone or in combination for acute mania. Cochrane Database of Syst Rev 2013: CD005000.

27. Correll CU, Sheridan EM, DelBello MP. Antipsychotic and mood stabilizer efficacy and tolerability in pediatric and adult patients with bipolar I mania: a comparative analysis of acute, randomized, placebo-controlled trials. Bipolar Disord 2010;12:116-41.

28. Ducharme Francine M, Ni Chroinin M, Greenstone I, Lasserson Toby J. Addition of long-acting beta2-agonists to inhaled corticosteroids versus same dose inhaled corticosteroids for chronic asthma in adults and children. Cochrane Database of Syst Rev 2010: CD005535.

29. Dwan K, Phillipi Carrie A, Steiner Robert D, Basel D. Bisphosphonate therapy for osteogenesis imperfecta. Cochrane Database of Syst Rev 2014: CD005088.

30. Fang $\mathrm{Y}, \mathrm{Wu} \mathrm{X}, \mathrm{Xu} \mathrm{L}$, et al. Randomized-controlled trials of levetiracetam as an adjunctive therapy in epilepsy of multiple seizure types. J Clin Neurosci 2014;21:55-62.

31. Ferracioli-Oda E, Qawasmi A, Bloch MH. Meta-analysis: melatonin for the treatment of primary sleep disorders. PLoS One 2013;8:e63773.

32. Hayward G, Thompson Matthew J, Perera R, Glasziou Paul P, Del Mar Chris B, Heneghan Carl J. Corticosteroids as standalone or add-on treatment for sore throat. Cochrane Database of Syst Rev 2012: CD008268.

33. Hidalgo RB, Tupler LA, Davidson JR. An effect-size analysis of pharmacologic treatments for generalized anxiety disorder. J Psychopharmacol 2007;21:864-72.

34. Jesner Ora S, Aref-Adib M, Coren E. Risperidone for autism spectrum disorder. Cochrane Database of Syst Rev 2007: CD005040.

35. Kim SO, Ah YM, Yu YM, Choi KH, Shin WG, Lee JY. Effects of probiotics for the treatment of atopic dermatitis: a meta-analysis of randomized controlled trials. Ann Allergy Asthma Immunol 2014;113:217-26.

36. Koh Mariko S, Tee A, Lasserson Toby J, Irving Louis B. Inhaled corticosteroids compared to placebo for prevention of exercise induced bronchoconstriction. Cochrane Database of Syst Rev 2007: CD002739. 
37. Lands Larry C, Stanojevic S. Oral non-steroidal anti-inflammatory drug therapy for lung disease in cystic fibrosis. Cochrane Database of Syst Rev 2013: CD001505.

38. Manning P, Gibson Peter G, Lasserson Toby J. Ciclesonide versus placebo for chronic asthma in adults and children. Cochrane Database of Syst Rev 2008: CD006217.

39. Mason Anne R, Mason J, Cork M, Dooley G, Hancock H. Topical treatments for chronic plaque psoriasis. Cochrane Database of Syst Rev 2013: CD005028.

40. Mbizvo Gashirai K, Dixon P, Hutton Jane L, Marson Anthony G. Levetiracetam add-on for drug-resistant focal epilepsy: an updated Cochrane Review. Cochrane Database of Syst Rev 2012: CD001901.

41. Normansell R, Walker S, Milan Stephen J, Walters EH, Nair P. Omalizumab for asthma in adults and children. Cochrane Database of Syst Rev 2014: CD003559.

42. Pulman J, Jette N, Dykeman J, Hemming K, Hutton Jane L, Marson Anthony G. Topiramate add-on for drug-resistant partial epilepsy. Cochrane Database of Syst Rev 2014: CD001417.

43. Ramaratnam S, Marson Anthony G, Baker Gus A. Lamotrigine add-on for drug-resistant partial epilepsy. Cochrane Database of Syst Rev 2001: CD001909.

44. Southern Kevin W, Barker Pierre M, Solis-Moya A, Patel L. Macrolide antibiotics for cystic fibrosis. Cochrane Database of Syst Rev 2012: CD002203.

45. Spooner C, Saunders LD, Rowe Brian H. Nedocromil sodium for preventing exercise-induced bronchoconstriction. Cochrane Database of Syst Rev 2002: CD001183.

46. Suttajit S, Srisurapanont M, Maneeton N, Maneeton B. Quetiapine for acute bipolar depression: a systematic review and meta-analysis. Drug Des Devel Ther 2014;8:827-38.

47. Tonia T, Mettler A, Robert N, et al. Erythropoietin or darbepoetin for patients with cancer. Cochrane Database of Syst Rev 2012: CD003407.

48. Tsapakis EM, Soldani F, Tondo L, Baldessarini RJ. Efficacy of antidepressants in juvenile depression: meta-analysis. Br J Psychiatry 2008;193:10-7.
49. Walters EH, Gibson Peter G, Lasserson Toby J, Walters Julia AE. Longacting beta2-agonists for chronic asthma in adults and children where background therapy contains varied or no inhaled corticosteroid. Cochrane Database of Syst Rev 2007: CD001385.

50. Watts K, Chavasse Richard JPG. Leukotriene receptor antagonists in addition to usual care for acute asthma in adults and children. Cochrane Database of Syst Rev 2012: CD006100.

51. Whiting P, Al M, Burgers L, et al. Ivacaftor for the treatment of patients with cystic fibrosis and the G551D mutation: a systematic review and costeffectiveness analysis. Health Technol Assess 2014;18:1-106.

52. Evers S, Marziniak M, Frese A, Gralow I. Placebo efficacy in childhood and adolescence migraine: an analysis of double-blind and placebo-controlled studies. Cephalalgia 2009;29:436-44.

53. Rutherford BR, Mori S, Sneed JR, Pimontel MA, Roose SP. Contribution of spontaneous improvement to placebo response in depression: a metaanalytic review. J Psychiatr Res 2012;46:697-702.

54. Suchman AL, Ader R. Classic conditioning and placebo effects in crossover studies. Clin Pharmacol Ther 1992;52:372-7.

55. McDonald CJ, Mazzuca SA, McCabe GP Jr. How much of the placebo 'effect' is really statistical regression? Stat Med 1983;2:417-27.

56. Whalley B, Hyland ME. Placebo by proxy: the effect of parents' beliefs on therapy for children's temper tantrums. J Behav Med 2013;36:341-6.

57. Cohen D, Deniau E, Maturana A, et al. Are child and adolescent responses to placebo higher in major depression than in anxiety disorders? A systematic review of placebo-controlled trials. PLoS One 2008;3:e2632.

58. Lewis DW, Winner P, Wasiewski W. The placebo responder rate in children and adolescents. Headache 2005;45:232-9.

59. Higgins JPT, Green S. Cochrane Handbook for Systematic Reviews of Interventions. 5.1.0 (updated March 2011). The Cochrane Collaboration, 2011. (http://handbook.cochrane.org/).

60. Jadad AR, Enkin MW. Randomized Controlled Trials: Questions, Answers and Musings. 2nd edn. Oxford, UK: Blackwell Publishing Ltd, 2007: $48-61$. 